$\underline{\text { Original Article }}$

\title{
FORMULATION AND EVALUATION OF TOPICAL ANTIFUNGAL GEL CONTAINING ITRACONAZOLE
}

\section{POONAM MADHUKAR KASAR*, KALYANISUNDARRAO KALE, DIPTI GANESH PHADTARE}

\author{
R. G. S Institute of Pharmacy, Anjaneri, Nashik, Maharashtra, India \\ Email: sonikasar2706@gmail.com
}

Received: 22 Apr 2018, Revised and Accepted: 10 Jun 2018

\begin{abstract}
Objective: The present research has been undertaken with the aim to develop a topical gel formulation of Itraconazole. Itraconazole is an imidazole derivative and used for the treatment of local and systemic fungal infection. The oral use of Itraconazole is not much recommended as it has many side effects. Commercially Itraconazole topical gel preparation are not available in the market, thus this formulation is made for better patient compliance and to reduce the dose of the drug and to avoid the side effects like liver damage and kidney damage.
\end{abstract}

Methods: The gel was formulated by changing the polymer ratio. Various formulation (F1, F2, F3, F4, F5) were developed by using a suitable polymer (carbopol 934p and HPMC). The formulation was evaluated for \% yield, spreadability, extrudability, wash ability and viscosity in vitro drug release study, skin irritation study, stability testing.

Results: Viscosity studies of various formulations revealed that formulation F3 was better to compare to others. From among all the developed formulation, F3 shows better drug diffusion, did good Rheological properties. pH of the F3 formulation is sufficient enough to treat the skin infections. Results indicated that the concentration of carbopol-934 and HPMC K4M significantly affects drug release and rheological properties of the gels.

Conclusion: It was concluded that formulation F3 was the best formulation among this formulation. Hence formulation F3 should be further developed for scale-up to industrial production.

Keywords: Itraconazole, Carbopol 934p, HPMC

(C) 2018 The Authors. Published by Innovare Academic Sciences Pvt Ltd. This is an open access article under the CC BY license (http://creativecommons.org/licenses/by/4.0/) DOI: http://dx.doi.org/10.22159/ijcpr.2018v10i4.28470

\section{INTRODUCTION}

Fungal infection of the skin is nowadays one of the common dermatological problems. The physicians have a wide choice for treatment from solid dosage to semisolid dosage form and to liquid dosage formulation. Among the topical formulation, clear transparent gels have widely accepted in both cosmetics and pharmaceuticals [1]. Topical treatment of dermatological disease as well as skin care, a wide variety of vehicle ranging from solids to semisolids and liquids preparations is available to clinicians and patients. Within the major group of semisolid preparations, the use of transparent gels has expanded both in cosmetics and in pharmaceutical preparation [2]. For many decades treatment of an acute disease or a chronic illness has been mostly accomplished by delivery of drugs to patients using various pharmaceutical dosage forms, including tablets, capsules, pills, suppositories, cream, gel, ointments, liquids, aerosols and injectable, as drug carriers. Delivery of drugs to the skin is an effective and targeted therapy for local dermatological disorders. This route of drug delivery has gained popularity because it avoids first-pass effects, gastrointestinal irritation, and metabolic degradation associated with oral administration. Due to the first past effect, only $25-45 \%$ of the orally administered dose reaches the blood circulation. In order to bypass these disadvantages, the gel formulations have been proposed as a topical application. Gels are defined as "semisolid system in which a liquid phase is constrained within a polymeric matrix in which a high degree of physical and chemical cross-linking introduced".
Itraconazole is a synthetic antifungal agent of the imidazole class; it works by slowing the growth of fungi that cause infection. It is used to treat fungal infection. Triazole drug targets the fungal-specific synthesis of membrane lipids. Itraconazole inserts preferentially into fungal membranes and disrupts their function. 5-fluorocytosine targets fungal-specific DNA replication [3]. Hydroxypropyl methylcellulose (HPMC), Carbapol 934p, has been used as hydrophilic polymers topically in gel drug delivery system [4].

\section{MATERIALS AND METHODS $[5,6]$}

\section{Material}

Itraconazole, HPMC, carbopol934, trimethanolamine, glycerine, Methylparaben, propylparaben, water.

\section{Method}

Polymer (like Carbopol 934p or HPMC) and purified water were taken in a beaker and allowed to soak for $24 \mathrm{~h}$. To this required amount of drug (2 gm) was dispersed in water and then Carbopol 934p or HPMC was then neutralized with sufficient quantity of Triethanolamine. Glycerine as a moistening agent, methylparaben and Propylparaben as preservatives were added slowly with continuous gently stirring until the homogenous gel was formed.

Gel formulations of Itraconazole were prepared using different concentrations of carbopol934, HPMC.

Table 1: Optimized formulae of Itraconazole gel

\begin{tabular}{|c|c|c|c|c|c|c|c|c|c|}
\hline \multirow[t]{2}{*}{ Formulation code } & \multicolumn{9}{|c|}{ Ingredients } \\
\hline & Drug & Carbopol & HPMC & Water & Alcohol & Methyl & Propyl & Glycerine & Triethanol \\
\hline F1 & 2 & 1 & - & 60 & 4 & 0.1 & 0.05 & 10 & 4 \\
\hline F2 & 2 & 1 & - & 60 & 4 & 0.1 & 0.05 & 10 & 4 \\
\hline F3 & 2 & 0.5 & 0.75 & 60 & 4 & 0.1 & 0.05 & 10 & 4 \\
\hline F4 & 2 & 0.5 & 0.5 & 60 & 4 & 0.1 & 0.05 & 10 & 4 \\
\hline F5 & 2 & 0.75 & 0.5 & 60 & 4 & 0.1 & 0.05 & 10 & 4 \\
\hline
\end{tabular}




\section{Evaluation of itraconazolegel [7-24]}

\section{Percentage Yield}

The empty container was Weighed in which the gel formulation was stored then again the container was weighed with gel formulation. Then subtracted the empty container weighed with the container with gel formulation then it gives the practical yield. Then the percentage yield was calculated by the formula.

$$
\text { Percentage yield }=\frac{\text { Practical yield }}{\text { Theoretical yield }} \times 100
$$

\section{Drug content}

Weighed $10 \mathrm{gm}$ of each gel formulation were transferred in $250 \mathrm{ml}$ of the volumetric flask containing $20 \mathrm{ml}$ of alcohol and stirred for $30 \mathrm{~min}$. The volume was made up to $100 \mathrm{ml}$ and filtered. $1 \mathrm{ml}$ of the above solution was further diluted to $10 \mathrm{ml}$ with alcohol and again $1 \mathrm{ml}$ of the above solution was further diluted to $10 \mathrm{ml}$ with alcohol. The absorbance of the solution was measured spectrophotometrically at $260 \mathrm{~nm}$. Drug content was calculated by the following formula

$$
\text { Drug content }=\frac{\text { Absorbance }}{\text { Slope }} \times \text { Dilution factor } \times \frac{1}{1000}
$$

\section{Determination of $\mathbf{P h}$}

Weighed $50 \mathrm{gm}$ of each gel formulation were transferred in $10 \mathrm{ml}$ of the beaker and measured it by using the digital $\mathrm{pH}$ meter. $\mathrm{pH}$ of the topical gel formulation should be between 3-9 to treat the skin infections.

\section{Spreadability}

The spreadability of the gel formulation was determined, by measuring the diameter of $1 \mathrm{gm}$ gel between horizontal plates $(20 \times 20 \mathrm{~cm} 2)$ after 1 minute. The standardized weight tied on the upper plate was $125 \mathrm{gm}$.

\section{Extrudability}

The gel formulations were filled into a collapsible metal tube or aluminium collapsible tube. The tube was pressed to extrude the material and the extrudability of the formulation was checked.

\section{Viscosity estimation}

The viscosity of gel was determined by using a Brookfield viscometer DVII model with a T-Bar spindle in combination with a helipath stand.

a) Selection of spindle: Spindle T 95 was used for the measurement of viscosity of all the gels.

b) Sample container size: The viscosity was measured using $50 \mathrm{gm}$ of gel filled in a $100 \mathrm{ml}$ beaker.

c) Spindle immersion: The T-bar spindle (T95) was lowered perpendicular in the centre taking care that spindle does not touch the bottom of the jar.

d) Measurement of viscosity: The T-bar spindle (T95) was used for determining the viscosity of the gels. The factors like temperature, pressure and sample size etc. Which affect the viscosity was maintained during the process. The helipath T-bar spindle was moved up and down giving viscosities at a number of points along the path The torque reading was always greater than $10 \%$. The average of three readings taken in one minute was noted as the viscosity of gels.

\section{In vitro diffusion study}

The abdominal skin of Albino mice, weighing 20-25 gm of 8-10 w old was shaved using hand razor and clean the skin with hot water cotton swab. $5 \mathrm{gm}$ of gel was applied uniformly to the skin. The skin was mounted between the compartments of the Frantz diffusion cell with stratum corneum facing the donor compartment. Reservoir compartment was filled with $100 \mathrm{ml}$ phosphate buffer of $\mathrm{pH}$ 6.8. The study was carried out at $37 \pm 1^{\circ} \mathrm{C}$ and the speed was adjusted until the vortex touches the skin and it carried out for $4 \frac{1}{2} \mathrm{~h} .5 \mathrm{ml}$ of the sample was withdrawn from the reservoir compartment at 30 min interval and absorbance was measured spectrophotometrically at $260 \mathrm{~nm}$. Each time the reservoir compartment was replenished with the $5 \mathrm{ml}$ volume of phosphate buffer $\mathrm{pH} 6.8$ solution to maintain a constant volume.

\section{RESULTS AND DISCUSSION}

Table 2: Percent yield of gel formulations

\begin{tabular}{ll}
\hline Formulation & Percent yield \\
\hline F1 & $99.59 \%$ \\
F2 & $98.34 \%$ \\
F3 & $97.44 \%$ \\
F4 & $99.81 \%$ \\
F5 & $98.76 \%$ \\
\hline
\end{tabular}

Table 3: Drug content of gel formulations

\begin{tabular}{ll}
\hline Formulation code & Drug content \\
\hline F1 & 94.41 \\
F2 & 97.38 \\
F3 & 98.24 \\
F4 & 96.52 \\
F5 & 95.07 \\
\hline
\end{tabular}

Table 4: pH of gel formulations

\begin{tabular}{ll}
\hline Formulation & Ph \\
\hline F1 & 6.98 \\
F2 & 7.01 \\
F3 & 6.98 \\
F4 & 6.5 \\
F5 & 6.79 \\
\hline
\end{tabular}


Table 5: Viscosity of gel formulations

\begin{tabular}{ll}
\hline Formulation & Viscosity(cp) \\
\hline F1 & 8476 \\
F2 & 4259 \\
F3 & 4450 \\
F4 & 4544 \\
F5 & 6.79 \\
\hline
\end{tabular}

Table 6: Spreadability of gel formulations

\begin{tabular}{lll}
\hline Formulation & Spreadability \\
\cline { 2 - 3 } & R1 & R2 \\
\hline F1 & 1.3 & 1.9 \\
F2 & 2.1 & 2.9 \\
F3 & 19 & 2.8 \\
F4 & 1.7 & 2.3 \\
F5 & 1.5 & 2.1 \\
\hline
\end{tabular}

Table 7: Extrudability of gel formulations

\begin{tabular}{ll}
\hline Formulation & Extrudability \\
\hline F1 & + \\
F2 & +++ \\
F3 & +++ \\
F4 & ++ \\
F5 & ++ \\
\hline
\end{tabular}

Excellent (+++), Good (++), Average (+), Poor (-)

Table 8: In vitro diffusion chart

\begin{tabular}{|c|c|c|c|c|c|}
\hline \multirow[t]{2}{*}{ Time } & \multicolumn{5}{|c|}{$\%$ CDR } \\
\hline & F1 & F2 & F3 & F4 & F5 \\
\hline 0 & 0 & 0 & 0 & 0 & 0 \\
\hline 30 & 12.95 & 16.87 & 14.88 & 14.03 & 13.67 \\
\hline 60 & 39.51 & 44.39 & 41.39 & 40.76 & 40.05 \\
\hline 90 & 47 & 48.49 & 47.95 & 47.02 & 46.91 \\
\hline 120 & 56.59 & 56.01 & 57.18 & 56.24 & 55.74 \\
\hline 150 & 62.84 & 61.28 & 63.59 & 62.31 & 61.89 \\
\hline 180 & 71.84 & 72.69 & 73.26 & 72.13 & 71.84 \\
\hline 210 & 80.17 & 79.37 & 82.15 & 81.68 & 80.86 \\
\hline 240 & 87.27 & 86.16 & 89.07 & 88.19 & 87.98 \\
\hline 270 & 95.98 & 94.09 & 97.03 & 96.83 & 96.03 \\
\hline
\end{tabular}

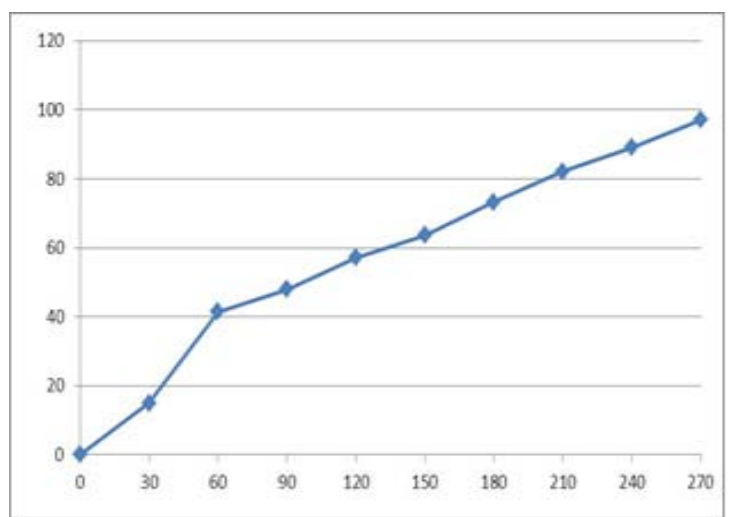

Fig. In vitro diffusion for F3 formulation

\section{CONCLUSION}

Various formulation (F1, F2, F3, F4, F5) were developed by using a suitable polymer (carbopol 934p and HPMC). Developed formulations of Itraconazole were evaluated for the physiochemical parameters such as percentage yield, drug content, $\mathrm{pH}$, viscosity, spreadability, extrudability, in vitro drug diffusion. Viscosity studies of various formulations revealed that formulation F3 was better to compare to others. From among all the developed formulation, F3 shows better drug diffusion, did good Rheological properties. pH of the F3 formulation is sufficient enough to treat the skin infections. Results indicated that the concentration of carbopol-934 and HPMC K4M significantly affects drug release and rheological properties of the gels. The viscosity of carbopol-934 gels was very high as compared to HPMC K4M gels but both gels showed a decrease in drug release with an increase in polymer concentration. Thus, gels can be successfully prepared using carbopol-934 and Hydroxypropyl methylcellulose as gelling agents in the ratio 1:3(carbopol-934 and Hydroxypropyl methylcellulose) suitable for topical application Hence formulation F3 should be further developed for scale-up to industrial production.

\section{AUTHORS CONTRIBUTIONS}

All the author have contributed equally

\section{CONFLICT OF INTERESTS}

Declared none

\section{REFERENCES}

1. Provost C. A review on transparent oil-water gels. Int J Cosmet Sci 1986;8:233-47. 
2. Gupta A, Mishra AK, Singh AK, Gupta V, Bansal P. Formulation and evaluation of topical gel of diclofenac sodium using different polymers. Drug Invention Today 2010;2:250-3.

3. Gerry Fink and the Fink lab. How antifungal drug kill fungi and cure disease; 2005. Available from: URL: http://www. medscape.com/viewprogram/296 3-pn. [Last accessed on 09 Feb 2005].

4. Golinkin HS. Process for fracturing well formulation using aqueous gels. US Patent, US 4137182; 1979.

5. Singh MP, Nagori BP, Shaw NR. Formulation development and evaluation of topical gel formulations using different gelling agents and its comparison with marketed gel formulation. Int J Pharm Erud 2013;3:1-10.

6. B Niyaz Basha, Kalyani P, Divakar G. Formulation and evaluation of gel containing fluconazole-antifungal. Int J Drug Dev Res 2011;3:109-12.

7. Doaa AH, Dalia AE, Sally AA, Mohamed AE. Formulation and evaluation of fluconazole topical gel. Int J Pharm Pharm Sci 2012;4:176-83.

8. Sudipta DA, Arnab SA, Ananya BO. Design, development and evaluation of fluconazole topical gel. Asian J Pharm Clin Res 2015;8:132-13.

9. Ashni VE, Sukhdev SI, Rupinder KA, Upendra KJ. A review: topical gels as drug delivery systems. Int J Phrm Sci Rev Res 2013;23:374-82.

10. Prateek $\mathrm{CH}$, Rajesh ST, Umesh RA. A review on the topical gel. Int J Pharm Bio Agric 2013;4:606-13.

11. Loveleen PR, Tarun KG. Topical gel: a recent approach for novel drug delivery. Asian J Biomed Pharm Sci 2013;3:1-5.

12. Debjit B, Harish G, B Pragati, S Duraivel, KP Sampath Kumar. Recent advances in novel topical drug delivery system. Pharma Innovation 2012;1:12-31.
13. Roychowdhury S, Singh DH, Gupta R, Masih D. A review on the pharmaceutical gel. Int J Pharm Res Bio Sci 2012;1:21-36.

14. Loveleenpreet K, Prabhjot K. Formulation and evaluation of topical gel of meloxicam. Int J Res Pharm Chem 2014;4:619-23.

15. PK Lakshmi, Marka KK, Aishwarya S, Shyamala B. Formulation and evaluation of ibuprofen topical gel: a novel approach for penetration enhancement. Int J Appl Pharma 2011;3:25-30.

16. Joshi B, Gurpreet AC, Saini S, Singla V, Emulgel A. Comprehensive review on the recent advances in topical drug delivery. Int Res J Pharm 2011;2:66-70.

17. Arun RR, Elwin J, Jyoti H, Sreerekha S. Formulation and evaluation of Ketoprofen solid dispersion incorporated topical gels, Eur J Biomed Pharm Sci 2016;3:156-64.

18. Swetha CH, Sellappan VP, Narayana RG, Nagarjuna R Formulation and evaluation of clarithromycin topical gel. Int J Drug Dev Res 2013;5:194-202.

19. Ganesh M, Gouri D, Vijay G. Formulation and evaluation of herbal gels. Int J Nat Prod Res 2012;3:501-5.

20. Marwa HS, Ghada FM. Evaluation of topical gel bases formulated with various essential oils for antibacterial activity against methicillin-resistant staphylococcus aureus. Trop J Pharm Res 2013;12:877-84.

21. Aejaz A, Azmail K, Sanaullah S, Mohsin AA. Formulation and in vitro evaluation of aceclofenac solid dispersion incorporated gels. Int J Appl Pharm 2010;2:7-12.

22. Barhate SD, Potdar MB, Nerker P. Development of meloxicam sodium transdermal gel. Int J Pharm Res Dev 2010;2:1-7.

23. Bazigha AK, Eman AF, Sahar FA, Heyam SS, Saeed KA, Development and evaluation of Ibuprofen transdermal gel formulations. Trop J Pharm Res 2010;9:355-63.

24. Jain S, Padsalg BD, Patel AK, Mokale V. Formulation, development and evaluation of fluconazole gel in various polymer bases. Asian J Pharm 2007;1:3-8. 